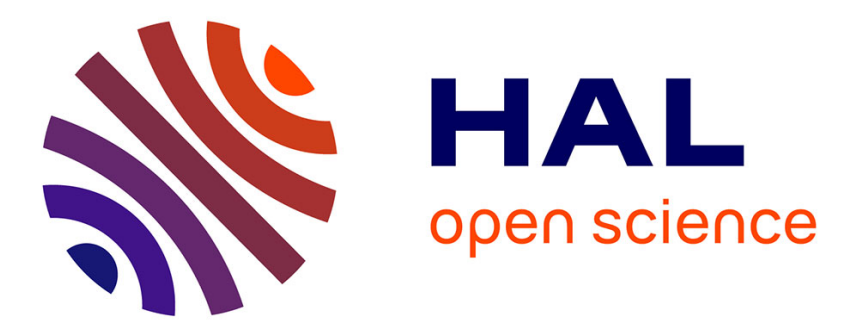

\title{
Towards Ontology-Aided Manufacturing and Supply Chain Management - A Literature Review
}

\author{
Stanislaw Strzelczak
}

\section{To cite this version:}

Stanislaw Strzelczak. Towards Ontology-Aided Manufacturing and Supply Chain Management - A Literature Review. IFIP International Conference on Advances in Production Management Systems (APMS), Sep 2015, Tokyo, Japan. pp.467-475, 10.1007/978-3-319-22759-7_54 . hal-01431134

\section{HAL Id: hal-01431134 \\ https://hal.inria.fr/hal-01431134}

Submitted on 10 Jan 2017

HAL is a multi-disciplinary open access archive for the deposit and dissemination of scientific research documents, whether they are published or not. The documents may come from teaching and research institutions in France or abroad, or from public or private research centers.
L'archive ouverte pluridisciplinaire HAL, est destinée au dépôt et à la diffusion de documents scientifiques de niveau recherche, publiés ou non, émanant des établissements d'enseignement et de recherche français ou étrangers, des laboratoires publics ou privés.

\section{(c)(1)}

Distributed under a Creative Commons Attribution| 4.0 International License 


\title{
Towards Ontology-Aided Manufacturing and Supply Chain Management - A Literature Review
}

\author{
Stanisław Strzelczak \\ Warsaw University of Technology, Faculty of Production Engineering, Warsaw, Poland \\ s.strzelczak@wip.pw.edu.pl
}

\begin{abstract}
Semantic technologies are recognized as crucial in those domains, which intensively exploit information and communication technologies (ICT) and automation technologies (AT). Ontology engineering means can facilitate new functionalities, organizational structures and processes. Intra- and interorganizational integration of different layers, functions, domains and processes may be simplified or enabled. Knowledge-driven solutions can be also facilitated. This paper investigates functional aspects of ontology-aided manufacturing and supply chain management by a literature review. The purpose is to assess potential for further research and to suggest its future key directions, aiming at novel solutions in terms of structures, controls, processes and functionalities.
\end{abstract}

Keywords. Ontology • Manufacturing management - Supply chain management $\bullet$ Semantic integration $\bullet$ Knowledge-driven management

\section{$1 \quad$ Introduction and methodology}

This work investigates advantages of ontologies as the means for semantic integration of operations management activities, particularly as facilitators of new provisions in terms of novel structures, processes and controls. Semantic technologies are recently recognized as crucial management technologies for those domains, which intensively exploit ICT and automation [27]. Ontologies support intra- and inter-organizational integration of different domains, functions, layers and processes. Ontologies enhance changeability, in reference to business resources and processes.

The main streams of industrial development in recent decades were to major extent supported by innovations in the ICT and AT area. The key enabling technologies with this regard were: smart/mobile solutions, Web services, Service-Oriented Architectures (SOA) and semantic technologies. In parallel, mostly due to globalization and technology revolution increasing openness was affecting various areas, hence driving complexity, like: spatial spread, networking, coupling, variability etc. These qualitative changes tended to act as generic determinants for considered developments. Hence extraordinary challenges and opportunities arise concerning development of operations resources, processes and systems. Handling various aspects of complexity provides another major issue for managing globalized operations. 
This paper provides literature review based state-of-the-art of using ontology-aided manufacturing and supply chain management. A functional, but not technical perspective is focused on. The objective herein is to assess the need and potential for further research and to suggest its future key directions, particularly aiming at novel solutions, i.e. in terms of structures, processes and controls. This research goes in parallel with a similar one, of industrial requirements but as seen by industries [21].

The number of published ontologies for manufacturing and logistics is limited. Many of them target specific areas, and only few address management and control manufacturing and logistical operations. All of them are reviewed below. Principally their scope, depth and targeted use are commented. Only the most representative papers from different research centers are refereed.

\section{Literature insights on manufacturing management ontologies}

This section reviews all ontologies for manufacturing operations management, that were accessible to the author.

The ontology of Soares et al. [26] focuses on production planning and control in a virtual enterprise to improve human communication and to support specification of system requirements. It is founded on meta-ontology, whereas the concepts are defined by natural language and object models.

Lemaignan et al. [16] presented MASON ontology (Manufacturing's Semantics Ontology), which is built upon three head concepts: resources, operations and entities. For each class several subclasses were defined.

Dassisti et al. proposed an ontology-based model which follows IEC 62264 standard [8]. It includes models for: (a) Product Definition; (b) Materials; (c) Equipment; (d) Personnel; (e) Processes Segments: it contains process segments that list the classes of personnel, equipment, and material needed; (f) Production Schedule: made up from one or more production requests; (g) Production Capability; (h) Production Performance. Extended conceptualizations were provided for two of the above classes.

Cândido et al. described the ontology for shop floor assembly [5]. Two categories of concepts were proposed: modules and skills. Modules represent physical processing units or their aggregation, i.e. compositions of workstations. Workstation is a composition of transforming, flow or verification units. Two constructs "composedof" and "is-a" are used to describe compositions and specialization relations. Skills represent abilities to perform operations. The basic element which uses ontology as a model for reasoning about objects and their relations is the Manufacturing Resource Agent (MRA). This agent searches ontology after instantiation for skills it supports. MRA agents can form coalitions to provide combined skills. In such case a Coalition Leader Agent coordinates execution of elementary actions by coalition members.

Obitko et al. proposed ontology for Agent-Based Manufacturing Systems [20]. The basic categories in it are: (a) customer order, (b) production plan, (c) workstation, transportation and material handling. All of them reuse classes and properties from the Core Ontology that for example separates physical and information resources. There are also other ontologies, such as ontology for the configuration of the system. 
Battista and Giordano [3] proposed a modeling framework which incorporates: (1) product and planning data (BOM - Bill of Materials, process charts, MPS (Master production Schedule), calendars etc.); (2) operations and equipment data; (3) production and inventory control policies; (4) distinction between physical and information layer. Although the above framework is not named as ontology, the authors advocate for using ontology of manufacturing system including the proposed elements.

Garetti and Fumagalli suggested three layers within their P-PSO ontology [11]: physical, technological and control. The main classes are: part; component (system structure); operation; controller (decisional element for production planning and control, i.e. be person, PLC or software); operator; subsystem (service class for grouping objects of classes). The ontology includes sound taxonomy of the transporter and storage sub-classes. Apart of the controller class the control aspect of the P-PSO ontology incorporates following classes: rule (logic of decision making: algorithm, heuristic, simple rule or knowledge-based rule); order (to be produced or purchased); production plan (set of orders generated by controller for time frame; it can be divided into sub-plans); batch; task (action of controller on component, part and operation classes, i.e. translation of controller actions at the physical level; e.g.: dispatching).

Al-Jumaili at al. investigated possibility of using ontologies in the context of eMaintenance aiming at easier exchange and better quality of maintenance data [1].

Krupa $[14,15]^{1}$, developed in 1980 s a complete conceptual framework for manufacturing and logistics rooted in the theories of sets, graphs, automata artificial intelligence formal linguistics. It uses two basic categories for describing the domain: resources and tasks. It is distinctive by many features, of which some were never addressed by the literature. The key of them are:

- Semiotic interpretation of resources (in terms of classes, objects and denotations).

- Distinction of transformation operations on the resources. Distinction of transformation-informative, structural and functional relations of resources. Distinction of systemic transformation operations on the resources.

- Consideration of other structuring formalisms for resources than those rooted in the theory of sets, e.g. collectivities of resources.

- Functional and automata-based interpretation of dynamic behavior of resources.

- Distinction of global /local (a priori, a posteriori) discrepancies between properties.

- Distinction of tacit (procedural) and explicit (structural) representation of tasks.

- Distinction of different forms of representation of tasks: procedural, predicate, operator, space of states, hypergraph, logistical model, mixed representations.

- Use of scenarios and logistical models of tasks and reasoning about them).

Although the term ontology was not used in Krupa's framework, it meets common definitions of ontology, i.e. it is a formal explicit description of concepts in a particular domain. It is descriptive in the Seidewitz's sense [25], and also prescriptive. To note, the dyadic construct of tasks and resources proposed by Krupa preceded the SOA paradigm.

${ }^{1}$ Krupa has mostly published in research reports of limited circulation. His contributions were summarized in the later of refereed publications. 
Vegetti et al. [28] and Giménez at al. [12] proposed an ontology for complex product modeling, which was expected to provide foundations for a distributed product data management supported by Semantic Web technology. The ontology suggests three abstraction levels for representing product-related concepts: product family, variant family and product (or physical item). A common formal vocabulary concerning product data that formalizes both processes of information aggregation and disaggregation that occurs during production planning activities is a focus herein.

Alsafi and Vyatkin [2] proposed an approach to achieve fast reconfiguration of modular manufacturing systems, based on an ontology-based reconfiguration agent. The agent uses ontological knowledge of the manufacturing environment for the purpose of reconfiguration without human intervention. It infers facts about the manufacturing environment from the ontological knowledge model and then decides whether the current environment can support the given manufacturing requirements. The knowledge model is based on previously mentioned MASON ontology.

All ontologies reviewed above are discussed together with the supply-chain ontologies in section 4 .

\section{$3 \quad$ Literature insights on ontology-aided supply chain management}

This section reviews all ontologies for supply chain operations management, that were accessible to the author.

Daniele and Pires Ferreira described core ontology for logistics focusing on the concept of physical resource [7]. A limited taxonomy of resources and their structures and some axioms in reference to relations between resources have been proposed.

Scheuermann and Hoxha proposed intelligent supply chain management (SCM) based on a combination of Semantic Web technologies and SOA [24]. They introduced dedicated ontology to semantically annotate logistics services using a threelayered model: (1) logistics ontologies providing foundation for defining formal semantics of consensual logistics knowledge; (2) semantic logistics service descriptions used for representation of atomic logistics services for description of service features and utilization of logistics ontologies of Layer 1 for semantic annotation; (3) atomic logistics services composed into complex logistics processes. This model includes elements to describe both, declarative and procedural aspects.

Madni et al. introduced the IDEON ontology to support design, reinvention, managing and controlling collaborative distributed enterprises [18]. IDEON integrates multiple perspectives, like enterprise context view or process view. It is presented in UML and conforms to simple taxonomies of resources and activities.

Leukel and Kirn developed a logistics ontology based on the SCOR model to capture core concepts of inter-organizational logistics [17]. The proposal facilitates description of activities in logistics and provides relations and attributes.

Haugen and McCarthy [13] proposed an extension of the REA (Resource-EventAgent) Ontology, which was originally designed for the accounting domain, to support Internet-based supply chain collaboration. 
Fayez et al. proposed a representation of the SCOR model for supply chain simulation developed in the OWL language [10]. The ontology captures the distributed knowledge being required to integrate several supply chain views in order to support the construction of simulation models. A further study of SCOR representation by means of ontology engineering is presented by Zdravković et al. [30].

Chandra and Tumanyan applied an ontology to systematically record knowledge about organizational and problem-specific issues for SCM [6]. They proposed an information modelling framework to create a taxonomy of supply chain problems and operations to alleviate operational uncertainty.

Pawlaszczyk et al. introduced an enterprise ontology to optimize interorganizational and distributed co-operations [22]. It is distinctively tailored to the mass customization environment and enables modelling of different scenarios concerning development or implementation of mass customization.

Ye et al. proposed a supply chain ontology (SCO) to enable semantic integration between heterogeneous supply chain information systems [29]. The supply chain setting is a web-based or virtual enterprise with no specific industry focus. The ontology is implemented in the OWL DL using the skeletal method to capture concepts and relationships of the domain. A rule-based approach is presented to map semantically similar terminologies between SCO and application ontologies.

Engel et al. proposed an ontology-based, knowledge-assisted platform to collaboratively create, adapt and control supply chain networks [9]. Such a platform is expected to reuse domain knowledge captured in previous supply chain projects and support simulation of various network configuration.

Mettler presented a formal ontology containing some concepts for analyzing manufacturing networks as service systems [19]. The ontology consists of sixteen key constructs like business areas, functions, roles, partners, goals, success factors, performance indicators, incentives, various resources and processes. For every construct a short description, exemplary instances or sub-classes, and the relations to other constructs is defined. They are formalized using OWL and RDF.

Sandkuhl et al. [23] investigated integration of information systems and production planning systems in enterprises with physical systems, like automation and control systems, into Cyber-Physical Systems (CPS) with focus on the logistics domain and on the service-oriented approach. The core proposal is a generic architecture for Logistics-as-a-Service systems (LaaS), representing elements of the logistics network as services. It is enriched with concepts from competence management and ontology matching. Ontology-based competence profiles are proposed for representing individual and organizational competences. Ontology matching contributes to configuring and finding resources in LaaS. Within the ontological representation of services and competences, multi-lingual ontology matching was also proposed.

Brock et al. discussed application of semantic modeling to allow free flow of models that are used along planning and control within a logistical network [4]. Their approach is intended to improve the productivity of logistical modeling in reference to operations management and control.

All ontologies reviewed in this section are discussed all together with the manufacturing ontologies in the next section. 


\section{$4 \quad$ Findings and conclusions}

Most of the publications reviewed in the two preceding sections address focus on some narrow or specific aspects, or are limited to few, and often abstract concepts. Many of them provide a limited description of ontologies and remain high-level. Other apply ontology languages upon existing models. Such narrow focuses are somehow understandable, as papers normally have to be of a limited size. But after a closer analysis of details in these publications it is unquestionable that most authors do not target anything else but rather initial and rough vision of the ontology.

Almost all papers avoid important but difficult aspects of the domain, e.g. details of planning and controlling operations, dynamics and behavioral issues of production networks and supply chains, etc. The non-hierarchical paradigm is also rarely addressed. Under-specifications are never incorporated into discussed conceptualizations.

Most publications lack rich formal semantics. Description logic is rarely used. Limited taxonomies usually lack formal axioms. Decision making is mostly not discussed. The service-oriented paradigm is bypassed or even neglected. The potential of semiotic interpretation of resources, tasks and other classes is rarely explored.

The most important research gap identified is in reference to the dynamic behaviors of systems and processes within the domain It particularly refers to representation of complexities and discrepancies that may arise along planning, controlling or execution of operations. Among them the following are typical: correlations, interdependencies, synchronizations, static and dynamical (temporary) fits and conflicts, blockings, starvations etc. The roots of them are analyzed by the literature to a very limited extent, if at all, like e.g.: layout driven limitations to flows; dynamic transformations of temporarily coupled resources and tasks (orders, flows etc.). Only one of the reviewed papers considers distinction of enduring and perduring classes of the resources and tasks and it indirectly provides spatiotemporal mereotopology of transforming operational tasks and resources.

On the other hand, all reviewed publications exhibit enabling potential of ontologies. However, it is mostly understood narrowly, i.e. in reference to direct advantages of ontologies, like provision of better performance, improved changeability, and other gains from utilization of knowledge or new functionalities. Systemic advantages that may lead to novel solutions in terms of system architectures, processes and controls are rarely investigated, and if at all than not in-depth. There are good reasons to argue that research concerning ontology-aided operations management for manufacturing and logistics is not as advanced, as - to compare - in the field of medical informatics.

The above conclusions fully justify following recommendations for further research concerning the discussed domain:

1. Development of core ontology for manufacturing and logistics operations management that could facilitate domain, sub-domain or application ontologies.

2. Development of ontologies equipped with spatiotemporal and mereotopological transformational abstractions to represent dynamic and spatial complexities arising along operations management, and exploiting advantages of the SOA paradigm. 
3. Development of new conceptualizations for various and diverse structures of resources (from systems to collectivities), processes (aiming changeability), and planning and control of operations (using alternative and novel control structures and rules, like heterarchical, distributed, herd or local controls).

4. Addressing cross-organizational operations management (i.e. beyond MRP/ERP).

5. Exploiting advantages of localized, globalized or outsourced (public) intelligence, and also the potential of merging ontologies and Big Data capacities.

6. Adapting current mode of operations management to local and temporary factors.

Acknowledgement: This work has been co-funded by the PSP 504/02105/1103/ 40.000105 grant of Warsaw University of Technology and by the EU ARTEMIS project no. 332946 "ESCOP - Embedded systems for Service-based Control of Open manufacturing and Process automation". The author thanks to partners of the projects.

\section{References}

1. Al-Jumaili, M, Wandt K, Karim, R.: eMaintenance ontologies and data production. In: Proc. of $2^{\text {nd }}$ Int'l Workshop \& Congress on eMaintenance, Luleå, 191-196 12-14.XII.2012

2. Alsafi, Y., Vyatkin, V.: Ontology-based reconfiguration agent for intelligent mechatronic systems in flexible manufacturing. Computer Integrated Manufact., 26, 381-391 (2010)

3. Battista, C., Giordano, F., Iannone, R., Schiraldi, M.: A proposal for a standard framework for simulating and modelling manufacturing systems. In: Digiesi, S., Mossa, G., Mummolo, G., Ranieri, L. (Eds): Sustainable Development: Industrial Practice, Education and Research, vol. 2 (2010)

4. Brock, D.L., Schuster, E.W., Allen, S.J., Kar, P.: An Introduction to Semantic Modeling for Logistical Systems. Journal of Business Logistics, Vol. 26/2, pp. 97-117 (2009)

5. Cândido, G., Barata, J.A.: Multiagent Control System for Shop Floor Assembly. Lecture Notes in Artificial Intelligence, 4659, pp. 293-302, Springer (2007)

6. Chandra, C., Tumanyan, A.: Organization and problem ontology for supply chain information support system. Data \& Knowledge Engineering, vol. 61, 2007/V. 263-280 (2007)

7. Daniele, L., Pires Ferreira, L.: An Ontological Approach to Logistics, In: Zelm, M., van Sinderen, M., Ferreira Pires, L., Doumeingts, G. (Eds): Enterprise Interoperability. John Wiley \& Sons, pp. 199-213 (2013)

8. Dassisti, M., Panetto, H, Tursi, A., De Nicolo, M.: Ontology-Based Model for ProductionControl Systems Interoperability. In: Proceedings of the $5^{\text {th }}$ CIRP International Conference on Digital Enterprise Technology (2008)

9. Engel, T., Venkatesh, V., Goswami, S., Krcmar, H., Bhat, M.: An Ontology-based Platform to Collaboratively Manage Supply Chains. In: Proceedings of the International Conference on Production and Operations Management (POMS'2014), Production and Operations Management Society, Atlanta, 2014/VIII (2014)

10. Fayez, F., Rabelo, L., Mollaghasemi, M.: (2005) Ontologies for supply chain simulation modeling. In: Proc. $37^{\text {th }}$ Conference on Winter simulation (WSC'05), 2364-2370, 2005/12

11. Garetti, M., Fumagalli, L.: P-PSO ontology for manufacturing systems. In: Proc. of $14^{\text {th }}$ IFAC Symposium on Information Control Problems in Manufacturing, 247-254 (2012)

12. Giménez, D., Vegetti, M., Henning, G., Leone, H.: PRoduct ONTOlogy. Defining productrelated concepts for production planning activities. In: Marquardt, W., Pantelides, C. 
(Eds), Proc. of $16^{\text {th }}$ European Symposium on Computer Aided Process Engineering and $9^{\text {th }}$ International Symposium on Process Systems Engineering, Elsevier, 2219-2225 (2006)

13. Haugen, R., McCarthy, W.E.: REA - a Semantic model for Internet Supply Chain Collaboration. In: ACM Conference on Object-Oriented Programming, Systems, Languages, and Applications, Business Objects and Component Design and Implementation Workshop VI: Enterprise Application Integration, 2000/X (2000)

14. Krupa, T.: Method of Task model (in Polish). In: Proceedings of the Int'l Conference on Production Systems (SYPRO'84), Warsaw Univerisity of Technology, Warsaw (1984)

15. Krupa, T.: Elements of organization: resources \& tasks (in Polish). WNT, Warsaw (2006)

16. Lemaignan, S., Siadata, A., Dantan, J.-Y., Semenenko, A.: Mason: A Proposal for an Ontology of Manufacturing Domain. In: Proceedings of the IEEE Workshop on Distributed Intelligent Systems, pp. 195-200 (2006)

17. Leukel, J., Kirn, S.: A Supply Chain Management Approach to Logistics Ontologies in Information Systems. In: Proceedings of the $11^{\text {th }}$ International Conference on Business Information Systems (BIS08), LNBIP, 2008/V, pp. 95-105. Springer (2008)

18. Madni, A.L., Lin, W., Madni, C.C. IDEON TM: an extensible ontology for designing, integrating and managing collaborative distributed enterprises. Systems Engineering, vol. 4, 2001/II, pp. 35-48 (2001)

19. Mettler, T.: Understanding Manufacturing Networks as Service Systems: An Ontological Approach. In: Proceedings of the International Conference on Advances in Production Management Systems (APMS'2010), Cernobbio (2010)

20. Obitko, M., Vrba, P., Mařik, V., Radakovič, M., Kadera, P.: Applications of Semantics in Agent-Based Manufacturing Systems. Informatica, vol. 34, pp. 315-330 (2010)

21. Olivieri, M., Strzelczak, S., Crestani, L., Zyskowski, D., Lederbuch, P., Soppera, F., Camp, R., Samborska, P., Pala, S. Gaps among industrial requirements and existing automation solutions. Deliverable D2.3, EU Grant no.332946, eScop: Embedded systems Service-based Control for Open manufacturing and Process automation (2013)

22. Pawlaszczyk, D., Dietrich, A.J., Timm, I.J., Otto, S., Kirn, S. Ontologies Supporting Cooperation in Mass Customization - A Pragmatic Approach. In: Proc. Int'l Conf. on Mass Customization and Personalization - Theory and Practice in CE, 2004/IV, pp. 1-19 (2004)

23. Sandkuhl, K., Lin, F., Shilov, N., Smirnov, A., Tarasov, V., Krizhanovsky, A.: Logisticsas-a-Service: Ontology-Based Architecture and Approach. Revista Investigacion Operacional, vol. 34/3, pp. 188-194 (2013)

24. Scheuermann, A., Hoxha, J.: Ontologies for Intelligent Provision of Logistics Services. In: Proc. $7^{\text {th }}$ Conference on Internet and Web Applications and Services (ICIW) (2012)

25. Seidewitz, E.: What models mean, IEEE Trans.Softw.Engineering, vol. 20/5, 26-32 (2003)

26. Soares, A.L., Azevedo, A.L., De Sousa, J.P.: Distributed planning and control systems for the virtual enterprise: organizational requirements and development life-cycle. Journal of Intelligent Manufacturing, vol. 11/6, pp. 253-270 (2000)

27. Strzelczak S (2014). Ontology-Aided Management. Silesian University of Technology Series in Management, 73, pp. 619-630 (2014)

28. Vegetti, M., Henning, G., Leone, H.: PRoduct ONTOlogy. An Ontology for Complex Product Modeling Domain. In: Proc. of ENPROMER 2005, Río de Janeiro (2005)

29. Ye, Y., Yang, D., Jiang, Z., Tong, L.: An Ontology-based Architecture for Implementing Semantic Integration of Supply Chain Management. International Journal of Computer Integrated Manufacturing, vol. 21/1, pp. 1-18 (2008)

30. Zdravković, M., Trajanović, M., Panetto, H.: Local Ontologies for Semantic Interoperability in Supply Chain Networks. In: Proceedings of the $13^{\text {th }}$ International Conference on Enterprise Information Systems (ICEIS'2011), Beijing (2011) 